\title{
ON CONVERGENCE PROPERTIES OF GAMMA-STANCU OPERATORS BASED ON $q$-INTEGERS
}

\author{
ÖZGE DALMANOĞLU AND MEDIHA ÖRKCÜ
}

Abstract. In this paper we introduce Stancu type generalization of Gamma operators based on the concept of $q$-integers. We first establish local approximation theorems for these operators. Next, we investigate the weighted approximation properties and give an estimate for the rate of convergence using classical modulus of continuity. Lastly, we obtain a Voronovskaya type theorem.

Mathematics subject classification (2010): 41A25, 41A36.

Keywords and phrases: Gamma operators, $q$-calculus, rate of convergence, weighted approximation, Voronovskaya type theorem.

\section{REFERENCES}

[1] A. Aral, V. Gupta, R. P. Agarwal, Applications of q-Calculus in Operator Theory, Springer, 2013.

[2] D. Aydin, A. Aral and G. BaşCanbaz-Tunca, A Generalization of Post-Widder Operators Based on q-Integers, Annals of the Alexandru Ioan Cuza University-Mathematics.

[3] Q. B. CAI AND X. M. ZENG, On the convergence of a kind of q-gamma operators, J. Inequal. Appl. 2013.1 (2013), 1-9.

[4] Q. B. CAI, Properties of Convergence for a Class of Genralized q-Gamma Operators, J. Math. Study 47, 4 (2014), 388-395.

[5] A. D. GADJIEV, A problem on the convergence of a sequence of positive linear operators on unbounded sets and theorems that are analogous to PP Korovkin's theorem, Dokl. Akad. Nauk SSSR. 218 (1974), 1001-1004.

[6] F. H. JACKSON, A generalization of the functions $\Gamma(n)$ and $x^{n}$, Proc. Roy. Soc. London 74, (1904), $64-72$.

[7] V. G. Kac And P. Cheung, Quantum Calculus, Universitext. Springer, New York, 2002.

[8] H. KARSLI, Rate of convergence of a new gamma type operators for functions with derivatives of bounded variation, Math. Comput. Model. 45, 5-6 (2007), 617-624.

[9] H. KARSLI, V. GUPTA AND A. İZGI, Rate of pointwise convergence of a new kind of gamma operators for functions of bounded variation, Appl. Math. Letters 22, 4 (2009), 505-510.

[10] H. KARSLI AND M. A. ÖZARSLAN, Direct local and global approximation results for operators of gamma type, Hacet. J. Math. Stat. 39 (2010), 241-253.

[11] H. Karsli, P. N. AgRawal And M. Goyal, General Gamma type operators based on q-integers, Applied Mathematics and Computation 251 (2015), 564-575.

[12] A. LuPAŞ, A q-analogue of the Bernstein operator, Seminar on Numerical and Statistical Calculus, University of Cluj-Napoca, 9 (1987), 85-92.

[13] S. M. MAZHAR, Approximation by positive operators on infinite intervals, Mathematica Balkanica $\mathbf{5}$, 2 (1991), 99-104,

[14] G. M. PhILliPS, Bernstein polynomials based on the q-integers, The heritage of P. L. Chebyshev, Ann. Numer. Math. 4 (1997), 511-518.

[15] A. D. SOLE AND V. KAC, On the integral representation of the q-gamma and the q-beta functions, Rendiconti Lincei: Matematica e Applicazioni 9, 16, 1 (2005), 11-19. 
[16] A. D. SOlE AND V. KAC, On integral representations of q-gamma and q-beta functions, arXiv preprint math/0302032 (2003).

[17] D. D. Stancu, Approximation of functions by a new class of linear polynomial operators, Rev. Roumaine Math. Pures Appl. 13 (1968), 1173-1194.

[18] J. Thомае, Beitrage zur Theorie der durch die Heinesche Reihe, J. Reine Angew. Math, 70 (1869), $258-281$.

[19] Z. Ünal, M. A. ÖZarslan, O. Duman, Approximation properties of real and complex Post-Widder operators based on q-integers, Miskolc Math. Notes 13 (2012), 581-603.

[20] X. M. ZENG, Approximation properties of Gamma operators, J. Math. Anal. Appl., 311 (2005), 389401.

[21] C. ZhaO, W. T. Cheng, X. M. Zeng, Some approximation properties of a kind of q-Gamma Stancu operators, J. Inequal. Appl. (94) (2014). 